\title{
Comparison between the micronucleus frequencies of kidney and gill erythrocytes in tilapia fish, following mitomycin $\mathrm{C}$ treatment
}

\author{
Dario Palhares and Cesar Koppe Grisolia \\ Departamento de Genética e Morfologia, Instituto de Ciências Biológicas, Universidade de Brasília, \\ Brasilia, DF, Brazil.
}

\begin{abstract}
The frequencies of mitomycin $\mathrm{C}$ and cyclophosphamide-induced kidney and gill erythrocyte micronuclei were compared in Tilapia rendalli and Oreochromis niloticus. Cyclophosphamide (CP) and mitomycin C (MMC) were previously used to investigate fish sensitivity to micronuclei induction in kidney erythrocytes. Fish were treated with a single dose of cyclophosphamide $(40 \mathrm{mg} / \mathrm{kg})$ or mitomycin C $(2 \mathrm{mg} / \mathrm{kg})$. Peripheral blood samples and kidney blood samples were obtained, 1, 2, 3, 5, 7, and 15 days after the intra-abdominal injection of MMC. T. rendalli showed to be more sensitive than $O$. niloticus to micronuclei production. Both compounds were used at the maximum tolerated dose (MTD), and mitomycin C proved to be more toxic than cyclophosphamide. The frequency of micronucleated erythrocytes observed varied significantly among the treated individuals. The difference between the kidney and gill micronuclei frequencies was not significant. Higher levels of micronucleated erythrocytes were observed in Tilapia rendalli than in $O$. niloticus. $T$. rendalli produced erythrocytes with deformed nuclei, which $O$. niloticus did not.
\end{abstract}

Key words: fish micronuclei, cyclophosphamide, mitomycin C, Tilapia rendalli, Oreochromis niloticus.

Received: November 12, 2001; accepted: June 14, 2002.

\section{Introduction}

Fish serve useful as genetic models for the evaluation of pollution in aquatic ecosystems (Mitchell and Kennedy, 1992; and Park et al., 1993). The erythrocyte micronucleus test has been used with different fish species to monitor aquatic pollutants displaying mutagenic features (De Flora et al., 1993). Kligerman (1982) demonstrated that fish inhabiting polluted waters have greater frequencies of micronuclei. The micronuclei frequencies may vary according to the season, the kind of pollution involved, and the species of fish. In laboratory tests involving fish, several substances have been shown to have genotoxic potential (Odeigah and Osaneyinpeju, 1995; Minissi et al., 1996), while others have proven innocuous (Belpaeme et al, 1996).

The micronuclei represent acentric chromosome fragments or whole chromosomes lost during cellular anaphase. These structures are easy to visualize in erythrocytes and are therefore often used as a measure of chromosomal aberrations (Rabello-Gay, 1991). In fish, the kidney is responsible for erythropoiesis as well as filtration. Upon fish exposure to toxins, defective erythrocytes undergo passage

Send correspondence to Cesar Koppe Grisolia, Instituto de Ciências Biológicas, Universidade de Brasília, 70910-900 Brasília, DF, Brazil. E-mail grisolia@unb.br. from the kidney into the peripheral blood, from where they are removed by the hemocatheresis organs. The hypothesis of this study was that the examination of kidney erythrocytes would provide earlier and more sensitive detection of micronuclei frequencies than peripheral blood erythrocytes. Accordingly, we analyzed the frequencies of micronuclei obtained from peripheral blood and from kidneis of Tilapia rendalli and Oreochromis niloticus, following induction by cyclophosphamide (CP) and mitomycin $\mathrm{C}$ (MMC) treatment.

\section{Materials and Methods}

Fish of the Tilapia rendalli and Oreochromis niloticus (Cyclidae) species, with an average size of $12 \pm$ $2 \mathrm{~cm}$ and an average weight of $100 \pm 5 \mathrm{~g}$, were caught in Lake Paranoá, an artificial reservoir in Brasilia, from 1996 through 1998. The base frequencies of micronuclei in peripheral erythrocytes were very low at all of the sampling sites (Grisolia and Starling, 2001). The Brasilia Water and Sewage Company continually monitors the quality of the water at those sites. The fish were brought to the laboratory and allowed to acclimatize for 5 days in $500 \mathrm{~L}$ tanks containing filtered, chlorine-free water, with constant aeration at $\mathrm{pH} 7.0$, and a temperature of $20 \pm 2{ }^{\circ} \mathrm{C}$. Mitomycin $\mathrm{C}$ was prepared in Ringer's solution at $0.4 \mathrm{mg} / \mathrm{mL}$ and injected at a 
dosage of $2 \mathrm{mg} / \mathrm{kg}$ of bodyweight. Cyclophosphamide was prepared at a concentration of $10 \mathrm{mg} / \mathrm{mL}$ in distilled water, and injected at $40 \mathrm{mg} / \mathrm{kg}$. Both compounds were injected intra-abdominally in a single dose. Compounds were previously tested to determine the maximum tolerated dose (MTD). Each treatment and control group was made up by six fish. Kidney blood from the fish treated with cyclophosphamide was obtained $1,2,3,5,7$, and 15 days after the treatment, and both peripheral and kidney blood were obtained from the groups treated with mitomycin C, 1, 2, 3, 5 , and 7 days after treatment.

The peripheral blood smears were obtained through the gills, and those of kidney blood by means of a medial-kidney imprint following dissection. The slides were air-dried for $12 \mathrm{~h}$ and then fixed in methanol for $10 \mathrm{~min}$, followed by $5 \%$ Giemsa (w/v) staining . Each fish had 2000 erythrocytes examined, from both peripheral blood and the kidney. To detect micronuclei in erythrocytes, the slides were analyzed using a 1000X oil-immersion lens. Statistical analysis was performed using Student's $t$ test.

\section{Results}

Mitomycin $\mathrm{C}$ at $2 \mathrm{mg} / \mathrm{kg}$ body weight was more toxic for $O$. niloticus than for $T$. rendalli, mainly between the third and the fifth post-inoculation days. At the MTD, some fish died within 5 days from treatment with mitomycin C. Treatments with mitomycin $\mathrm{C}$ at $2 \mathrm{mg} / \mathrm{kg}$ and cyclophosphamide at $40 \mathrm{mg} / \mathrm{kg}$ were considered to have reached the MTD for both species, because at these dosages signs of severe toxicity were observed, such as scale loss, refusal to feed and alteration in behavior.

The spontaneous micronuclei frequencies observed in kidney and in peripheral blood erythrocytes were statistically not different $(\mathrm{p}>0.05$, Table 2$)$. CP and MMC induced high frequencies of micronuclei in both species $(\mathrm{p}<0.05$, Tables 1 and 2). However, no difference between kidney and gill was observed, neither in $O$. niloticus, nor in T. rendalli $(\mathrm{p}=0.85$, Table 2$)$.

T. rendalli kidney erythrocytes treated with either mitomycin $\mathrm{C}$ or cyclophosphamide contained large numbers of nuclear deformities indicating cytotoxicity, not
Table I - Mean ( \pm S.E.) micronucleus frequencies (MN/1,000 kidney erythrocytes) in fish treated with cyclophosphamide

\begin{tabular}{lcc}
\hline & T. rendalli & O. niloticus \\
\hline control & $0.2 \pm 0.3$ & $0.4 \pm 0.4$ \\
1 day & $2.2 \pm 0.9^{*}$ & $1.6 \pm 0.8^{*}$ \\
2 days & $2.3 \pm 0.8^{*}$ & $1.6 \pm 0.6^{*}$ \\
3 days & $6.4 \pm 3.1^{*}$ & $2.1 \pm 0.4^{*}$ \\
5 days & $5.3 \pm 1.9^{*}$ & $1.3 \pm 1.0$ \\
7 days & $5.7 \pm 1.8^{*}$ & $0.3 \pm 0.4$ \\
15 days & $4.6 \pm 1.7^{*}$ & $0.7 \pm 1.0$ \\
\hline
\end{tabular}

* = significantly higher $(\mathrm{p}<0.05)$ than the control.

observed in cells from O. niloticus (Figure 1). T. rendalli responded faster to mitomycin $\mathrm{C}$, but the effects of cyclophosphamide lasted longer $(p=0.01)$. The maximum frequencies of CP-induced micronuclei in kidney erythrocytes were significantly lower in $O$. niloticus than in $T$. rendalli (Table 1). In O. niloticus, mitomycin C caused a greater increase in the number of micronuclei than cyclophosphamide $(\mathrm{p}<0.01)$, while in $T$. rendalli there was no significant difference between the maximum frequencies induced by the two drugs $(\mathrm{p}=0.70)$.

\section{Discussion}

In fish, the micronucleus test is usually based on erythrocytes, but liver and gill tissues have been used (Al-Sabti and Metcalfe, 1995). In mammals, young bone marrow erythrocytes can be distinguished quite easily from the mature ones by examining the Giemsa staining pattern of the cells. However, in fish, this distinction is not feasible. Rodriguez-Forero (1995) suggested that young fish erythrocytes stain as basophils with Giemsa. Observations made in our laboratory conditions agree with Ueda et al.'s (1992) findings that they are not distinguishable. The same authors (Ueda et al., 1992) counted fluorescent acridine-orangestained erythrocytes in the peripheral blood of fish, providing evidence that there is a significant volume of young erythrocytes in peripheral blood.

Table II - Mean ( \pm S.E.) micronucleus frequencies (MN/1,000 erythrocytes) in fish treated with mitomycin C.

\begin{tabular}{lcccc}
\hline & T. rendalli (gill) & T. rendalli (kidney) & O. niloticus (gill) & O. niloticus (kidney) \\
\hline Control & $0.4 \pm 0.3$ & $0.2 \pm 0.3$ & $0.2 \pm 0.3$ & $0.4 \pm 0.4$ \\
1 day & $7.6 \pm 2.7^{\mathrm{ab}}$ & $6.9 \pm 1.9^{\mathrm{ab}}$ & $2.2 \pm 1.2^{\mathrm{ab}}$ & $2.8 \pm 1.0^{\mathrm{ab}}$ \\
2 days & $5.7 \pm 2.5^{\mathrm{ab}}$ & $4.9 \pm 2.9^{\mathrm{ab}}$ & $2.1 \pm 1.3^{\mathrm{ab}}$ & $2.3 \pm 2.0^{\mathrm{ab}}$ \\
3 days & $1.8 \pm 1.8^{\mathrm{b}}$ & $1.8 \pm 1.8^{\mathrm{b}}$ & $3.8 \pm 1.7^{\mathrm{ab}}$ & $4.8 \pm 2.1^{\mathrm{ab}}$ \\
5 days & $1.4 \pm 0.8^{\mathrm{b}}$ & $1.3 \pm 1.8^{\mathrm{b}}$ & $2.7 \pm 1.1^{\mathrm{ab}}$ & $2.1 \pm 1.2^{\mathrm{ab}}$ \\
7 days & $3.0 \pm 2.2^{\mathrm{b}}$ & $2.3 \pm 1.5^{\mathrm{b}}$ & $2.1 \pm 1.0^{\mathrm{ab}}$ & $2.3 \pm 1.5^{\mathrm{ab}}$ \\
\hline
\end{tabular}

$\mathrm{a}=$ significantly higher $(\mathrm{p}<0.05)$ than the control.

$\mathrm{b}=$ not significantly higher $(\mathrm{p}=0.85)$, comparing gill and kidney. 


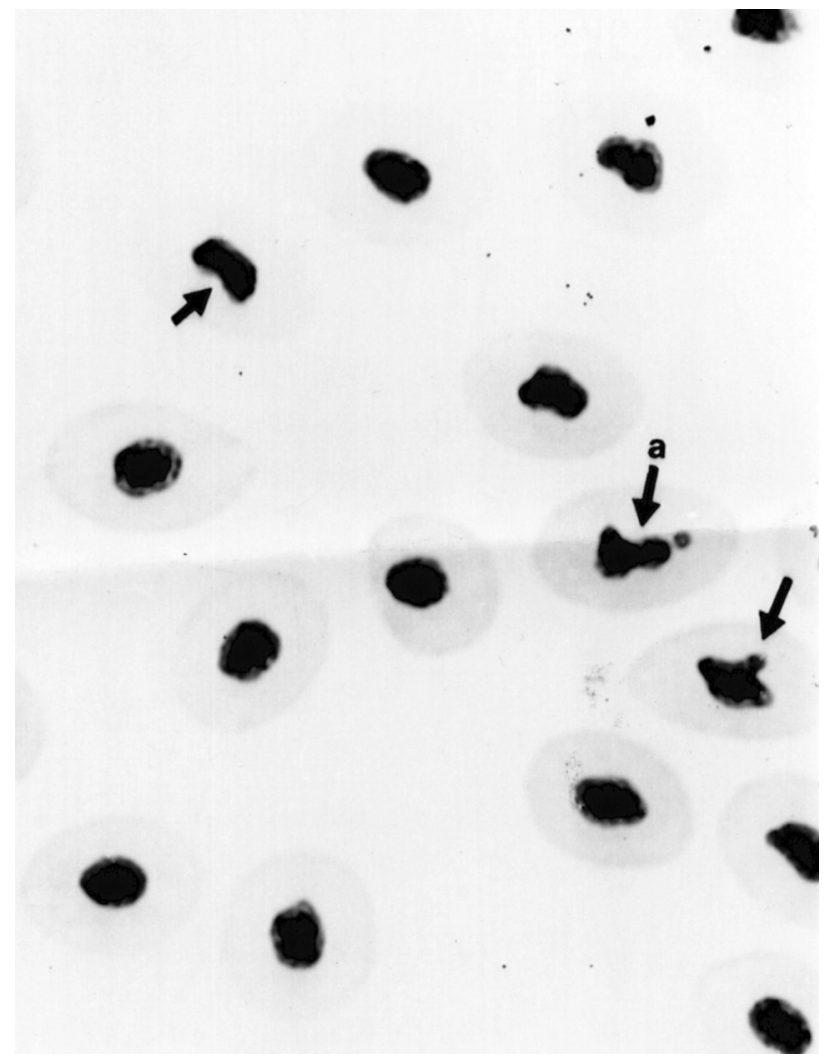

Figure 1 - Photomicrograph $(1000 \mathrm{X})$ of a kidney blood smear from $T$. rendalli treated with cyclophosphamide, showing a deformed and micronucleated erythrocyte nucleus (a), and two other erythrocytes with deformed nuclei (arrows).

Manna and Sadhukan (1986) compared the frequency of micronuclei in gill and kidney cells after irradiation, not detecting any statistically significant difference between the two tissues. While they included various types of cells, our study was focused on the erythrocytes. A hypothesis to explain the fact that we did not detect any difference between kidney and peripheral blood micronuclei counts may be that circulating peripheral erythrocytes also undergo mitosis. However, if the kidney is the main hemopoietic tissue in fish, and if micronuclei are formed during cell proliferation, more micronucleated erythrocytes should be expected in the kidney than in the gill. Alternatively, we may have sampled peripheral blood during kidney imprinting. The cephalic kidney is a frequently chosen organ for cytogenetic aberration studies in fish. However, for biomonitoring water mutagens, micronuclei analysis is more advantageous, because peripheral erythrocytes are as sensitive as kidney erythrocytes but easier to sample.

These results demonstrate that two close fish species can respond in completely different ways to a given genotoxic agent. $T$. rendalli produced an expressive number of kidney erythrocytes with deformed nuclei, and had significantly higher rates of micronuclei than $O$. niloticus. Depending on the toxic agent and on the species, the behavior of micronuclei rates may exhibit significant variations, probably related to the pharmacokinetics of the drugs used and to the speed of the hemopoietic cycle. Therefore, it is suggested that micronuclei tests in fish erythrocytes be carried out at various times following treatments, thus making it possible to follow-up the changing micronuclei frequencies. Studies of the micronuclei rates of various fish species showed that they generally peaked between the first and fifth days after treatment (Al-Sabti and Metcalfe, 1995; Grisolia and Cordeiro, 2000). We also conclude from this study that the sampling of peripheral blood is appropriate and sufficient for biomonitoring projects, as it allows to collect several samples from the same individual, without having to sacrifice it.

\section{Acknowledgments}

The authors thank Ornil Claro Costa for his technical assistance. This work was supported in part by Fundação de Apoio a Pesquisa do Distrito Federal (FAP-DF). The work of Dario Palhares was financed by a CNPq scholarship.

\section{References}

Al-Sabti K and Metcalfe C (1995) Fish micronuclei for assessing genotoxicity in water. Mutat Res 343:121-135.

Belpaeme K, Delbeke K, Zhu L and Kirsch-Volders M (1996) Cytogenetic studies of PCB77 on brown trout (Salmo trutta fario) using the micronucleus test and the alkaline comet assay. Mutagenesis 11:485-492.

De Flora S, Vigario L, D'Agostini F, Camoirano A, Bagnasco M, Bennecelli C, Melodia F and Arillo A (1993) Multiple biomarkers in fish exposed in situ to polluted river water. Mutat Res 319:167-177.

Grisolia CK and Cordeiro CMT (2000) Variability in micronucleus induction with different mutagens applied to several species of fish. Genetics and Molecular Biology 23(1):235-239.

Grisolia CK and Starling FLRM (2001) Micronuclei monitoring of fishes from Lake Paranoá, under influence of sewage treatment plant discharges. Mutation Research 491:39-44.

Kligerman D (1982) Fishes as biological detectors of the effects of genotoxic agents. In: Mutagenicity: New Horizons in Genetic Toxicology, Heddle J (ed) Academic Press, New York, pp 435-456.

Manna G and Sadhukhan A (1986) Use of cells of gill and kidney of tilapia fish in micronucleus test. Current Science 55:498-501.

Minissi S, Ciccotti E and Rizzoni M (1996) Micronucleus test in erythrocytes of Barbus plebejus (Teleostei, pisces) from two natural environments: a bioassay for the in situ detection of mutagens in freshwater. Mutat Res 367:245-251.

Mitchell S and Kennedy S (1992) Tissue concentrations of organochlorine compounds in common seals from the coast of Northern Ireland. Science of the Total Environment 115:235-240.

Odeigah C and Osaneyinpeju O (1995) Genotoxic effects of two industrial effluents and ethylmethane sulfonate in Clarias lazera. Food and Chemical Toxicology 33:501-505.

Park E, Lee J, YIA and Etoh H (1993) Fish cell line (ULF-23HU) derived from the fin of the central mudminnow (Umbra 
limi): suitable characteristics for clastogenicity assay. In Vitro Cell Developmental Biology 25:987-994.

Rabello-Gay MN (1991) Teste do micronúcleo em medula óssea. In: Mutagênese, Teratogênese e Carcinogênese: Métodos e Critérios de Avaliação, Sociedade Brasileira de Genética (ed), pp 83-90.
Rodriguez-Forero A (1995) Basic hematology of Oncorhyncus mykiss (Salmonidae) in Cundinamarca, Colombia. Revista de Biologia Tropical 43:283-288.

Ueda T, Hayashi M, Ohtsuka Y, Nakamura T, Kobayashi J and Sofuni $T$ (1992) A preliminary study of the micronucleus test by acridine orange fluorescent staining compared with chromosomal aberration test using fish erythropoietic and embryonic cells. Water Science Technology 25:235-240. 